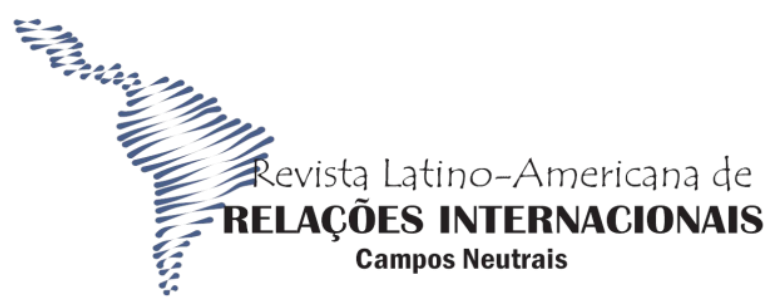

\title{
Catadores de materiais recicláveis e a Covid 19: impactos no trabalho diante da pandemia
}

Valéria Pereira Bastos*

Resumo: Este texto é produto de análises realizadas a partir da agudização das mazelas sociais produzidas pela pandemia de COVID 19, que descortinou inúmeras expressões da questão social no Brasil já vivenciada por milhões de trabalhadores formais e informais a partir da perda de direitos sociais agravada com o advento da crise sanitária. O recorte analítico voltou-se para área socioambiental, especificamente para analisar os impactos da pandemia no trabalho dos catadores de materiais recicláveis no país. Segmento que vem perdendo espaço na pauta pública em razão do descaso governamental e da doença no mundo, acabou também perdendo postos de trabalho em função da natureza da atividade, em que a contaminação pelo Novo Coronavírus é efetiva. Tomandose por base dados empíricos, pretendeu-se apontar velhos e novos desafios enfrentados por essa população, sobretudo na pandemia, a partir do sub-bairro de Jardim Gramacho, que abrigou por mais de três décadas o maior lixão da América Latina.

Palavras-Chave: Catadores de Materiais Recicláveis. Pandemia. Trabalho

\section{Recyclable material collectors and Covid 19: impacts on work in the face of the pandemic}

\begin{abstract}
This text is the product of analyzes carried out from the aggravation of social ills produced by the pandemic of COVID 19, which revealed numerous expressions of the social issue in Brazil already experienced by millions of formal and informal workers from the loss of social rights aggravated by the advent of the health crisis. The analytical focus turned to the socio-environmental area, specifically to analyze the impacts of the pandemic on the work of recyclable material collectors in the country. A segment that has been losing space on the public agenda due to government neglect and disease in the world, it also ended up losing jobs due to the nature of the activity, in which contamination by the New Coronavirus is effective. Based on empirical data, it was intended to point out old and new challenges faced by this population, especially in the pandemic, from the subneighborhood of Jardim Gramacho, which housed the largest dump in Latin America for more than three decades
\end{abstract}

Keywords: Recyclable Material Pickers. Pandemic. Work

\section{Introdução}

A inspiração para este estudo foi ensejada a partir do atual cenário de trabalho dos catadores de materiais recicláveis e reutilizáveis no Brasil diante da pandemia de Covid 19, com a finalidade de identificar os impactos nas atividades de coleta seletiva e na vida das famílias que são dependentes do trabalho desenvolvido por esse segmento que contabiliza no Brasil, segundo dados do MNCR (2019), cerca de 1 milhão de pessoas. A ideia é verificar quais ações têm sido realizadas pelo poder público no sentido de suprir as necessidades básicas desse segmento, uma vez que o trabalho de coleta e triagem de resíduos se constitui

\footnotetext{
* Doutora em Serviço Social - Professora Adjunta do Departamento de Serviço Social e Coordenadora do Programa de Pós-Graduação em Serviço Social da PUC-Rio. Pesquisadora apoiada pela Fundação de Amparo à Pesquisa do Estado do Rio de Janeiro - FAPERJ - Jovem Cientista. inscrita na ORCID ID 0000-0001-74120353 - CV Lattes: http://lattes.cnpq.br/0034189381343924
} 
Catadores de materiais recicláveis e a Covid 19: impactos no trabalho diante da pandemia Valéria Pereira Bastos

como um risco de contágio do Novo Coronavírus para os que participam da cadeia da reciclagem, sobretudo na atividade de triagem. Nesse processo, a contaminação não ocorre somente pelo contato físico, mas também por manuseio de objetos e, principalmente, de resíduos sólidos urbanos, exigindo novas alternativas de tratamento para prevenção e cuidados à saúde desses trabalhadores.

Cabe ressaltar que o atual cenário de pandemia da Covid 19 evidenciou o processo de agudização das manifestações da questão social, expressa por milhões de trabalhadores e trabalhadoras informais no Brasil, visto que grande parte são sujeitos desprovidos de direitos trabalhistas. Essa situação já vinha sendo agravada pelas sucessivas perdas no acesso aos direitos sociais, precarizando cada vez mais as atividades desenvolvidas nos diversos setores informais. Neste sentido, pretendemos dar relevância ao cenário socioambiental, em especial o trabalho de catadores e catadoras de materiais recicláveis na atividade de coleta seletiva dos resíduos sólidos urbanos.

\section{Covid 19 e Catadores}

Inicialmente, tomaremos como referência dados apresentados pela Associação Brasileira de Engenharia Sanitária e Ambiental - ABES (2020), coletados a partir da pesquisa realizada nos meses de março e abril de 2020, que registra, através do gráfico abaixo, os percentuais de suspeita de adoecimento, considerando as inúmeras subnotificações a respeito da doença de trabalhadores da área de resíduos sólidos infectados, bem como as áreas de maior contaminação:

Figura 1. Casos suspeitos de contaminação de trabalhadores da área de limpeza

Percentuais de casos suspeitos por setor de atividade até $31 / 5 / 20$

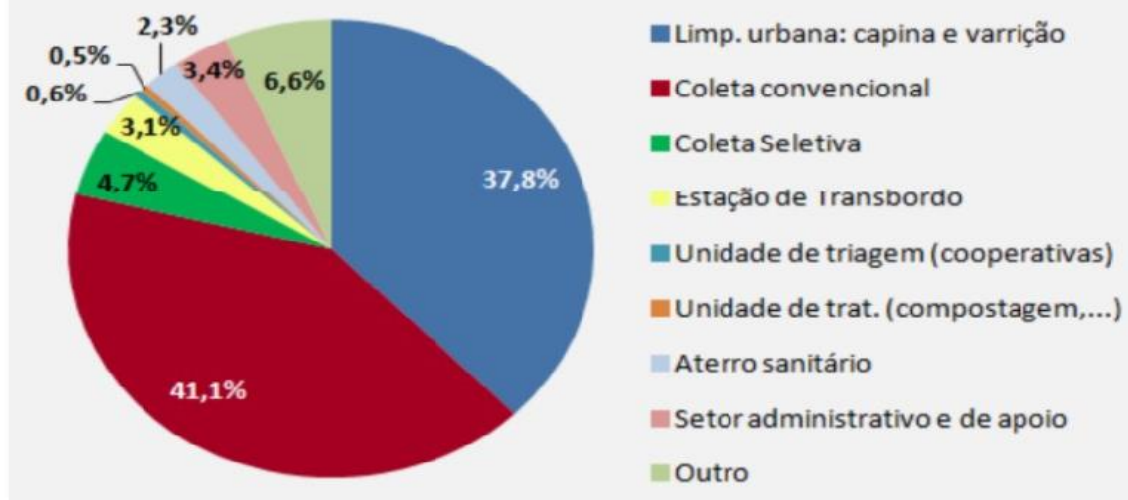

Fonte: ABES (2020) 


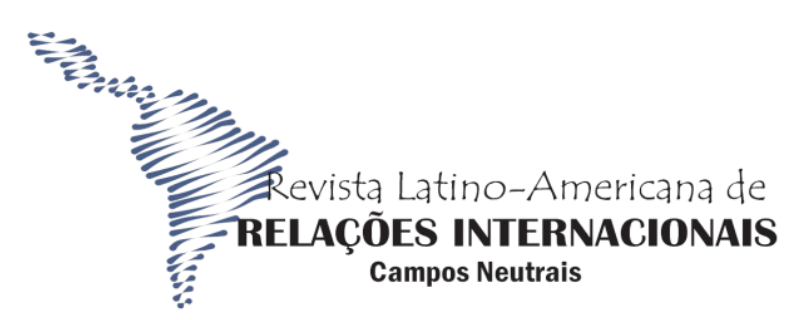

Tais índices nos apontam que, na realidade da catação, o processo de contaminação foi intensificado, considerando que $41.1 \%$ dos casos identificados concentram-se na área de coleta convencional, seguido de limpeza urbana, capina e varrição, com $37.8 \%$. Pontos que podem encontrar amparo técnico nas pesquisas realizadas por cientistas de várias Universidades e Centros de Pesquisa, uma das quais - a Universidade da Califórnia - Los Angeles aponta: "que o vírus sobrevive por três dias no aço inoxidável, 72 horas no plástico e 24 horas no papelão" (https://jornalzonasul.com.br/tempo-de-vida-do-virus-e-diferenteem-cada-material/).

Fator que podemos agregar, dentre outras justificativas, como inviabilizador do trabalho das cooperativas, diz respeito à parca infraestrutura para tratamento e higienização dos resíduos, pois elas não têm o potencial de higienização e armazenamento para todos os materiais potencialmente recicláveis e tampouco capital de giro para aguardar o período de quarentena para descontaminação e possibilidade da comercialização, evitando, dessa forma, ser o foco de maior contaminação. Como esses procedimentos não foram possíveis, os protocolos necessários não se efetivaram.

Neste sentido, a Política Nacional de Resíduos Sólidos - Lei 12.305/2010 -, que completou uma década em agosto de 2020, preceitua a importância das ações públicas de combate ao destino inadequado do lixo domiciliar, entre outros resíduos classificados no Brasil, determinando, em seu artigo 54, o encerramento de práticas inadequadas de destinação final de resíduos - mais conhecidas por "lixões" - e estipulando o prazo de quatro anos a contar da publicação da lei para seu total cumprimento. Com isso, traz à tona a obrigação, por parte dos gestores públicos, de promover o encerramento dos lixões e a implantação da gestão integrada de resíduos sólidos no município, o que na prática não ocorreu, conforme declara a ABRELPE (2019)², uma vez que ainda se contabiliza um total de 1552 municípios que utilizam essa modalidade em todo território nacional, em descumprimento à legislação.

Acreditamos que esses espaços também abrigam milhares de trabalhadores que - pela

\footnotetext{
${ }^{1}$ Lixão - É uma forma inadequada de disposição final de resíduos sólidos, que se caracteriza pela simples descarga do lixo sobre o solo, sem medidas de proteção ao meio ambiente ou à saúde pública. O mesmo que descarga de resíduos a céu aberto (IPT, 1995). Disponível em: <http://www.rc.unesp.br/igce/aplicada/ead/residuos/res12.html>. Acesso em: 22 nov. 2015.

${ }^{2}$ Associação Brasileira de Empresas de Limpeza Pública - Panorama dos Resíduos Sólidos Urbanos - última versão. Disponível em: <http://www.abrelpe.org.br/Panorama/panorama2019.pdf〉. Acesso em 22 nov. 2019. 
Catadores de materiais recicláveis e a Covid 19: impactos no trabalho diante da pandemia Valéria Pereira Bastos

via da informalidade - sobrevivem com suas famílias de forma insalubre, penosa e perigosa, sem nenhum amparo previdenciário, apenas, por vezes, cobertos pela política de assistência, em situações nas quais adquirem visibilidade, ou por compensações socioambientais, que na maioria das vezes são ações pontuais, sem ressonância no futuro das pessoas envolvidas.

Esses espaços podem ser caracterizados pelo que Dutra (2015), apud Acselrad, (2004) denomina zonas de sacrifícios: Para o autor,

\begin{abstract}
"zonas de sacrifício" e "paraísos de poluição" são termos utilizados para denominar localidades escolhidas para concentrar atividades que geram graves danos ambientais (ACSERALD, 2004). Não por acaso, essas localidades são as que abrigam também populações mais pobres, suas moradias, espaços de lazer e convivência, materializando a distribuição desigual dos riscos (DUTRA, 2015, p. 185).
\end{abstract}

O espelhamento dessa manifestação se traduz no racismo ambiental e se revela em expressões da questão social, representada por paraísos de poluição e/ou zonas de sacrifício, e podem ser traduzidos, conforme descreve Acselrad (2004), como:

\begin{abstract}
“objeto de uma concentração de práticas ambientalmente agressivas, atingindo populações de baixa renda. Os moradores dessas áreas convivem com a poluição industrial do ar e da água, depósitos de resíduos tóxicos, solos contaminados, ausência de abastecimento de água, baixos índices de arborização, riscos associados a enchentes, lixões e pedreiras. Nestes locais, além da presença de fontes de risco ambiental, verifica-se também uma tendência a sua escolha como sede da implantação de novos empreendimentos de alto potencial poluidor. Tais localidades são chamadas, pelos estudiosos da desigualdade ambiental, de "zonas de sacrifício" ou "paraísos de poluição", onde a desregulação ambiental favorece os interesses econômicos predatórios, assim como as isenções tributárias o fazem nos chamados "paraísos fiscais".

Nestes locais, observa-se a conjunção das decisões de localização de instalações ambientalmente danosas com a presença de agentes políticos

e econômicos empenhados em atrair para o local investimentos de todo tipo, qualquer que seja seu custo social e ambiental. Estes dois processos tendem a prevalecer em áreas de concentração de moradores de menor renda e menos capazes de se fazerem ouvir nos meios de comunicação e nas esferas de decisão." (ACSELRAD, 2004, p. 12-13).
\end{abstract}

Corroborando com que define Acselrad (2004). As palavras de Viegas (s/d) corroboram a discussão apresentada por Acselrad (2004), ratificando o descaso público, que ficou efetivamente evidenciado a partir da pandemia de Covid 19 em 2020:) "Na perspectiva dos estudiosos da desigualdade ambiental, o termo "zona de
sacrifício" passou a designar locais onde há ocorrência de múltiplas práticas
ambientalmente agressivas atingindo populações de baixa renda ou minorias
étnicas. Tais populações são vítimas de impactos indesejáveis de grandes
investimentos que se apropriam dos recursos existentes nos territórios, concentram
renda e poder, ao mesmo tempo em que atingem a saúde de trabalhadores e a 


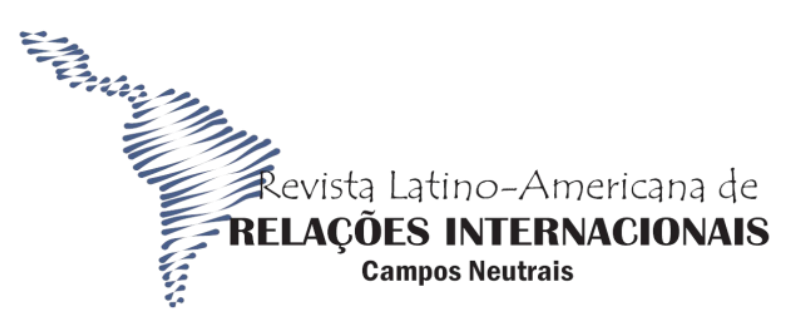

integridade de ecossistemas de que dependem. Como agravante, esses mesmos grupos, submetidos aos mais variados riscos ambientais, são aqueles que dispõem de menos condições de se fazerem ouvir no espaço público, não tendo oportunidade de colocar em questão os efeitos da desigual distribuição da poluição e da proteção ambiental "(VIEGAS, s/d, p. 20).

Neste contexto, consideramos que se torna imperativa a efetivação de políticas públicas que ofertem à população em geral, e não somente a uma parca parcela, condições dignas de vida e de trabalho, pois consideramos ser esta a única via de alcançar o reconhecimento social como cidadãos, tornando-os visíveis a (e dando-lhes) efetiva relevância enquanto pessoas, (;essa política deverá incluir os) trabalhadores da área ambiental, como é o caso dos catadores de materiais recicláveis, dada a atividade de coleta, triagem e semibeneficiamento de materiais potencialmente recicláveis realizadas por eles.

Por outro lado, ainda refletindo a respeito da situação dessa população de trabalhadores, que de forma precarizada sobrevivem a partir das sobras e rejeitos da população, ou da ação solidária, ressaltamos que a situação é contraditória, pois em vez de se ter ações para investir na formalização e profissionalização dos sujeitos, de um modo geral as práticas - sejam públicas ou privadas - se reproduzem de forma perversa, sem a devida atenção, conforme Silva (2010) assinala:

\footnotetext{
“Ao mesmo tempo em que assegura a contínua produção e reprodução da "questão ambiental - assim como ocorre com a questão social - o capital se empenha em atenuar as suas manifestações, administrando suas contradições através do impulsionamento de programas compensatórios, lastreados pelo discurso do solidarismo, do respeito aos direitos humanos e da defesa do meio ambiente" (SILVA, 2010, p. 143).
}

Diante da perversa realidade que esse contingente de trabalhadores se depara, a todo instante, no universo de seu trabalho, muito nos chamou atenção, buscar informações considerando o momento de pandemia. Sendo assim, fomos buscar fontes e dados que nos descortinassem o panorama atual.

Encontramos, então, a partir das informações veiculadas pelo Compromisso Empresarial para Reciclagem - CEMPRE (2020), alguns dados, visto que de 23 de março a 24 de abril de 2020 realizaram levantamento em quatrocentos e oito municípios do Brasil, apurando os impactos no trabalho das cooperativas de materiais recicláveis, sobretudo na vida dos catadores, .Assim, apurou-se que $63,4 \%$ das cooperativas tiveram paralisação total

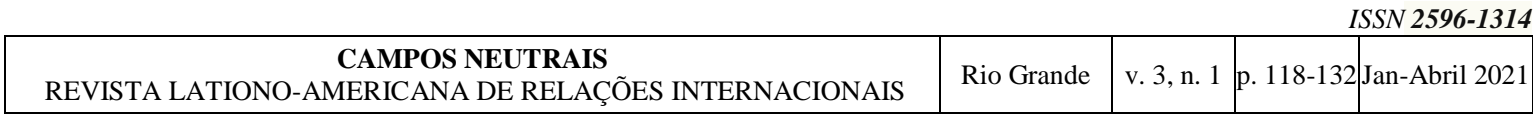


Catadores de materiais recicláveis e a Covid 19: impactos no trabalho diante da pandemia Valéria Pereira Bastos

e/ou parcial das atividades de coleta e triagem de resíduos sólidos, (;) porém, mais 12,7\% dos municípios, nos quais não existe o serviço de coleta seletiva, o que permite afirmar que o índice sobe para $76.1 \%$ de trabalhadores atingidos diretamente. A coleta direta nas ruas também foi impactada, considerando as orientações de distanciamento social e a consequente paralisação de grande parte dos serviços. Por sua vez, as demais cooperativas pesquisadas, ou seja, $23.9 \%$, tiveram os trabalhos parcialmente comprometidos, tendo em vista que o acesso à coleta e a triagem dos materiais foram interrompidos e estavam sendo enviados diretamente para os aterros sanitários (ABES, 2020).

$\mathrm{Na}$ busca de atualizar e/ou ampliar os dados, encontramos também informações veiculadas pela Associação Brasileira de Higiene Pessoal, Perfumaria e Cosméticos ABIHPEC, integrante do grupo do Acordo Setorial de Embalagens em $\mathrm{Geral}^{3}$, preceituado pelo Política Nacional de Resíduos Sólidos. No período de pandemia, a ABIHPEC vem apoiando cerca de cinco mil catadores, e realizou um levantamento em mais de 150 cooperativas em maio de 2020, (no qual assinala:

\begin{abstract}
“os números apontam que $98 \%$ estão com suas operações totalmente paralisadas por força de decretos ou recomendações sanitárias, ou ainda, com suas operações comprometidas devido à paralisação de coleta e a dificuldade ou impossibilidade de venda dos materiais. E mais, $88 \%$ dessas não contam com qualquer espécie de suporte temporário por parte de governos locais e estaduais" (HERNANDES, 2020." Disponível em: https://liderancacomvalores.com.br/coronavirusreciclagem/).
\end{abstract}

Somado aos dados acima, foi possível ainda constatar, de acordo com a segunda etapa da pesquisa (realizada pela ABES (2020), intitulada: O impacto da pandemia pela Covid na gestão dos resíduos sólidos urbanos nas capitais brasileiras, é que, em relação à implementação da política pública de coleta seletiva nos municípios brasileiros que já a tinham implantado, grande parte sofreu retrocesso:

\begin{abstract}
"Quanto à coleta seletiva, constatou-se que diversos municípios mantiveram restrições na coleta seletiva devido aos riscos que os catadores poderiam ter ao coletar e especialmente ao manusear os resíduos sólidos secos recicláveis. Assim aconteceu com Cuiabá, Brasília, Palmas, João Pessoa, São Luiz, Belo Horizonte e Salvador. Duas das capitais declararam não haver coleta seletiva no município, são elas Macapá e Boa Vista. O Rio de Janeiro e São Paulo, as maiores cidades do país, exibiram reduções de 7,9\% e 7,4\%, respectivamente. Próximo destes valores aparece Curitiba com 6,8\%" (ABES, 2020, p. 10).
\end{abstract}

\footnotetext{
${ }^{3}$ Acordo Setorial de Embalagens em Geral - Ferramenta legal prevista como parte integrante da Logística Reversa prevista na PNRS/2010 e celebrado em novembro de 2015 - Disponível em: https://sinir.gov.br/index.php/component/content/article/2-uncategorised/122-acordo-setorial-de-embalagensem-geral

\begin{tabular}{|c|c|c|c|c|}
\hline & & & & ISSN 2596-1314 \\
\hline $\begin{array}{c}\text { CAMPOS NEUTRAIS } \\
\text { REVISTA LATIONO-AMERICANA DE RELAÇÕES INTERNACIONAIS }\end{array}$ & Rio Grande & v. 3, n. 1 & p. $118-132$ & Jan-Abril 2021 \\
\hline
\end{tabular}
}




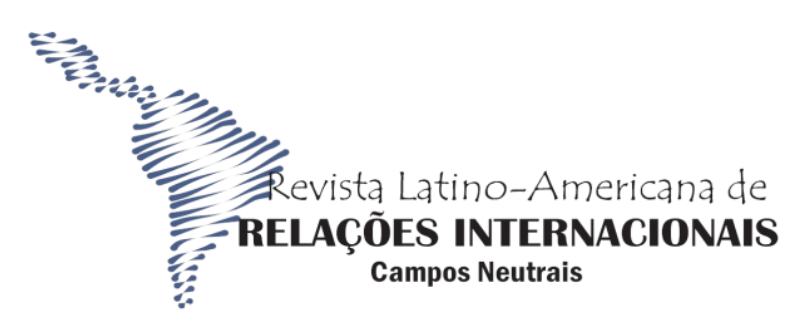

Embora a atual realidade do mercado de recicláveis permita cogitar um horizonte sustentável e economicamente atraente para o empresário da área de reciclagem, contraditoriamente, nega àquele que dá início à cadeia produtiva, o catador de material reciclável, o acesso a bens e serviços. Trata-se de uma atividade sem reconhecimento profissional no mercado de trabalho formal, desvalorizada, insalubre, perigosa, penosa e sem respaldo de direitos do trabalho, pois apesar de ser classificado como ocupação brasileira COB 5192-5, a profissão não foi reconhecida oficialmente.

Desse modo, a forma como esses trabalhadores são vistos ou ignorados socialmente carrega uma grande carga de estigmatização, e suas condições de vida revelam a efetiva necessidade da atuação de políticas públicas para atendimento das suas demandas de sobrevivência. A contribuição social e ambiental ofertada por meio da atividade de coleta e separação de resíduos sólidos, efetuada pelos catadores de resíduos, tem caráter útil incontestável, mas nem por isso torna o trabalho valorizado, com condições adequadas para sua realização, e tampouco promove melhoria na qualidade de vida desses trabalhadores, de forma que possam de fato ser inseridos (com dignidade) no processo produtivo.

Esses fatores ganham sustentação e aderência em nossa reflexão, porque apresentam expressões agudas da "questão social" entendida como mecanismos sucessivos de exploração da força de trabalho nos diferentes períodos da sociedade capitalista, que apesar de estar em estágio maduro, ainda mantém segmentos populacionais completamente alijados do direito ao trabalho regulado. A atividade de catador possui importância para o meio ambiente, mas, além disso, consiste numa expressão de luta pela sobrevivência.

A propósito, a sinalização feita por Henri Acselrad (2002), em sua reflexão a respeito de justiça ambiental e a construção de riscos, pode contribuir para nosso entendimento a respeito da necessidade de maior apoio público aos catadores, tendo em vista tratar-se de um segmento de trabalhadores informais que, após anos de trabalho, expostos a toda sorte de adversidades advindas da insalubridade e periculosidade decorrentes da atividade desempenhada, continuam à mercê dos riscos. Nas palavras de Acselrad,

\footnotetext{
“os sujeitos sociais que procuram evidenciar a importância de uma relação lógica entre injustiça social e degradação ambiental são aqueles que não confiam no mercado como instrumento de superação da desigualdade ambiental e da promoção dos princípios do que se entenderia por justiça ambiental. Estes atores consideram que há clara desigualdade social na exposição aos riscos ambientais, decorrente de uma lógica que extrapola a simples racionalidade abstrata das
} 
Catadores de materiais recicláveis e a Covid 19: impactos no trabalho diante da pandemia Valéria Pereira Bastos

tecnologias. Para eles, o enfrentamento da degradação do meio ambiente é o momento da obtenção de ganhos de democratização e não apenas de ganhos de eficiência e ampliação de mercado. Isto porque supõem existir uma ligação lógica entre o exercício da democracia e a capacidade da sociedade se defender da injustiça ambiental" (ACSELRAD, 2002, p.52).

Tais aspectos ganham maiores proporções em função do quadro de pandemia, visto que, segundo previsão da Organização para a Cooperação e Desenvolvimento Econômico OCDE, a economia brasileira deve apresentar queda de 7,4\% neste ano, que levará ao aumento contínuo do desemprego no país e à corrosão da renda dos brasileiros, que muito provavelmente afetará o comércio e a indústria, com redução do consumo e, consequentemente, da geração de resíduos, ponto abordado também na pesquisa da ABES (2020). Trata-se portanto de um cenário altamente preocupante - segundo a CEPAL e a OPAS, há uma previsão de aumento da pobreza na América Latina e no Caribe de 7\%, totalizando 37,3\% na região em 2021.

Sendo assim, além de haver a possibilidade de redução da geração de resíduos sólidos urbanos, poderá acontecer, caso não sejam tomadas medidas urgentes, um retorno de populações em situação de miserabilidade aos lixões, para a catação de materiais, gerando isso, além de um retrocesso de dimensões insustentáveis, um alto processo de poluição ambiental, o que comprometerá não somente os trabalhadores informais que dependem do garimpo dos recicláveis, mas também o contexto comunitário do entorno, assim como a atmosfera.

Neste sentido, ressaltamos que, apesar de a política pública de assistência social ter estabelecido o auxílio emergencial através do pagamento de $\mathrm{R} \$ 600,00$ para diversos segmentos, inclusive os trabalhadores informais, categoria em se enquadram os catadores e catadoras, grande parte não foi contemplada, uns devido ao comprometimento ou ausência de documentos; outros, pela dificuldade de acesso à rede de internet, gerando o que Martins (1997) denomina de inclusão precária:

\footnotetext{
"A sociedade capitalista "tem como lógica própria tudo desenraizar e a todos excluir porque tudo deve ser lançado no mercado". Ela desenraiza e exclui para depois incluir segundo as suas próprias regras. É justamente aqui que reside o problema: nessa inclusão precária, marginal e instável (MARTINS, 1997, pp. 3032). O período de passagem do momento da "exclusão" para o momento da "inclusão" implica certa degradação e, segundo Martins, a sociedade moderna vem criando uma grande massa de população sobrante que tem poucas chances de ser novamente incluída nos padrões atuais de desenvolvimento, ou seja, o período de passagem entre "exclusão" e "inclusão", que deveria ser transitório, vem se transformando num modo de vida permanente e criando uma sociedade paralela que é includente do ponto de vista econômico e excludente do ponto de vista social, moral e até político" (MARTINS, 1997, p. 33 e 34).
} 


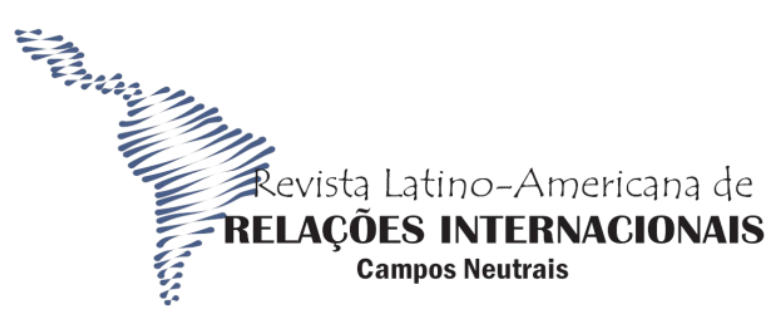

A aproximação do Estado, promovida após a Constituição de 1988, com a Sociedade Civil, que gerou, na década de 1990 e início dos anos 2000, uma ação estratégica central na implantação de políticas públicas, apesar de todas as contradições, está ameaçada diante dos retrocessos da conjuntura político-econômica brasileira de redução dos investimentos estatais em todas as áreas sociais, agudizada no período de pandemia, sobretudo em relação à pauta ambiental, que vem a cada dia sendo desmontada e desconsiderada como ponto da agenda nacional e internacional. Portanto, tal conjuntura não vem cumprindo o que Raichelis (1998) aponta como construção da esfera pública que deve transcender a forma estatal ou privada, remeter a novas formas de articulação entre Estado e Sociedade Civil, arranjos em que interesses coletivos possam ser confrontados e negociados, valorizando, assim, o entrosamento entre Estado e Sociedade Civil.

No capítulo XXIII do volume I de $O$ Capital, Marx considera, em sua obra mais importante, que desde o surgimento do capitalismo, segmentos da sociedade não fazem parte do mercado de trabalho devido à própria dinâmica societária instalada em seu modo de produção e de reprodução social. Na medida em que a composição orgânica do capital é alterada, trabalhadores são expulsos dos seus empregos e outros nem mesmo chegam a acessar a possibilidade de serem explorados. Esse traço social do modo de produção capitalista pode se modificar a depender da conjuntura política e econômica, mas jamais será superada. Fato que observamos na situação de extremo pauperismo de catadores e catadoras do Brasil, sobretudo na realidade de pandemia.

\section{Os catadores de Jardim Gramacho e os impactos da pandemia}

Figura 2. Mapa da Região Metropolitana do Rio de Janeiro

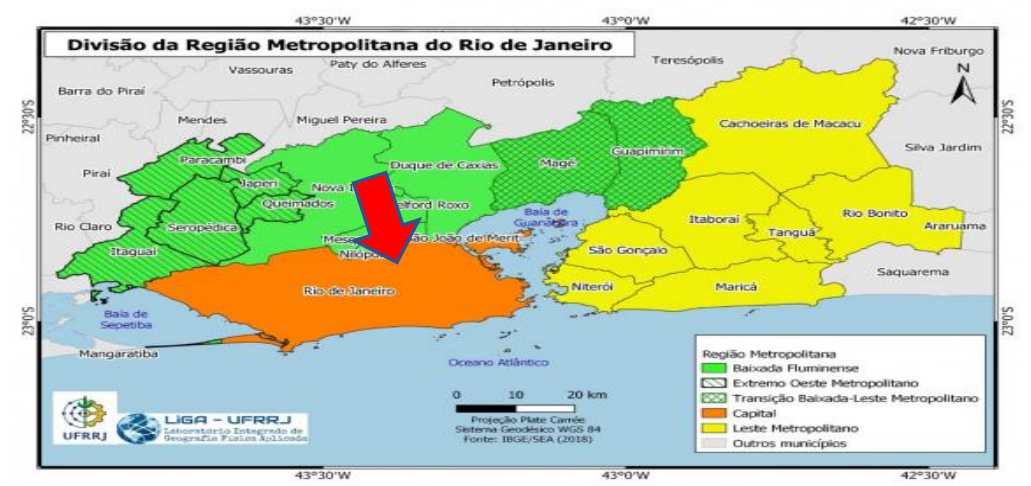

Fonte: https://journals.openedition.org/espacoeconomia/docannexe/image/13591/img-2.jpg 
Catadores de materiais recicláveis e a Covid 19: impactos no trabalho diante da pandemia Valéria Pereira Bastos

A Baixada Fluminense é um celeiro de miséria e precariedade, o que se acentua na pandemia; o Jardim Gramacho, por sua vez, se constitui como uma das zonas de sacrifício já mencionada, tendo abrigado por mais de três décadas o maior lixão da América Latina. Até os dias atuais, registra a presença de muitas atividades voltadas para triagem e comercialização de materiais recicláveis. Na busca de aproximar nossas reflexões da realidade, e tendo em vista o cenário apresentado naquela região, consideramos importante trazer alguns pontos decorrentes da pandemia e os impactos nas atividades dos catadores que ainda permanecem por lá.

Nossa preocupação se consubstancia na fala de Fortes e Oliveira (2020):

\begin{abstract}
"A Baixada Fluminense pode ser atingida por um verdadeiro tsunami de contaminados com a expansão metropolitana da pandemia da COVID-19. Essa dura previsão se deve a vários fatores: 1) A dinâmica da pandemia tem levado, em todo mundo, a uma dificuldade em acompanhar o número de infectados, e até mesmo de óbitos; 2) O Brasil deve presenciar, nas próximas semanas, o crescimento exponencial do número de infectados; 3) A COVID-19 se difundiu no Rio de Janeiro inicialmente entre segmentos com condições mais favoráveis, e tudo indica que ganhará uma dinâmica muito mais agressiva nas periferias urbanas; 4) A alta densidade demográfica, a precariedade das condições de vida e das unidades de saúde, assim como a influência de lideranças negacionistas tendem a agravar o impacto da doença na região" (FORTES, OLIVEIRA, 2020).
\end{abstract}

Diante dos fatos, consideramos relevante trazer todas essas questões para discussão, principalmente agora, com a pandemia de Covid 19, que reacendeu as inúmeras expressões da questão social, descortinando as mazelas existentes em localidades cujo acesso a bens e serviços já eram dificultados, e que com a crise sanitária foram agudizadas, colocando em uma maior evidência essas expressões.

Segundo Maria Ozanira da Silva e Silva (2010), a pobreza (grifo nosso) deve ser entendida como:

\footnotetext{
"fenômeno estrutural, complexo, de natureza multidimensional, relativo, não podendo ser considerado como mera insuficiência de renda é também desigualdade na distribuição da riqueza socialmente produzida; é não acesso a serviços básicos; à informação; ao trabalho e a uma renda digna; é não a (a não?) participação social e política” (SILVA, 2010).
}

$\mathrm{Na}$ busca de articular os conceitos já trabalhados com a realidade do sub-bairro em questão, consideramos importante trabalhar também o entendimento a respeito da questão socioambiental, pois para além de todo o estigma e condição de pobreza em que vive a população residente, o local carrega, até os dias atuais, pelo fato de ser reconhecido como território do lixo, as atividades e a economia que circulavam na época do lixão. Esse contexto

\begin{tabular}{|c|c|c|c|c|}
\hline $\begin{array}{c}\text { CAMPOS NEUTRAIS } \\
\text { REVISTA LATIONO-AMERICANA DE RELAÇÕES INTERNACIONAIS }\end{array}$ & Rio Grande & v. 3 , n. 1 & p. $118-132$ & 2 Jan-Abril 2021 \\
\hline
\end{tabular}




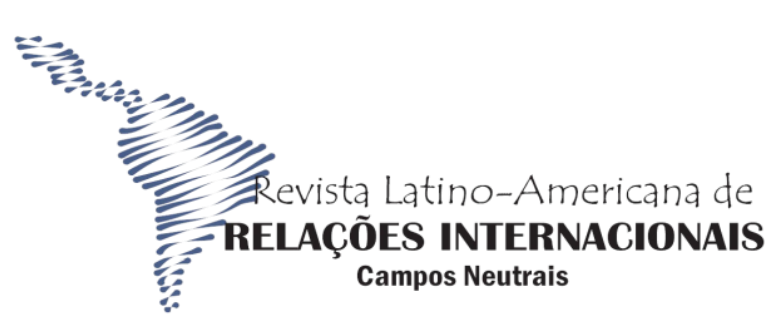

retrata de forma efetiva a sua essência, por se constituir como um território permeado por um: "conjunto de manifestações da destrutividade ambiental, resultantes da apropriação privada da natureza, mediadas pelo trabalho humano" (SILVA, 2010, p.144)". Sendo assim, a autora evidencia que o sócio (grifo nosso) inserido no ambiental (grifo nosso) é justificado com a finalidade de evidenciar uma opção política para reforçar a compreensão de que não se pode separar dessa discussão o componente social do ambiental.

Neste sentido, pensar a questão socioambiental a partir da vivência no sub-bairro de Jardim Gramacho implica considerar que os desafios que se colocam na atualidade estão longe de atingir a todos da mesma maneira. Isso porque a precarização do trabalho e a financeirização do capital têm contribuído significativamente para essa dinâmica, fazendo com que as classes empobrecidas, no caso, os catadores e catadoras de materiais reutilizáveis e recicláveis, e seus territórios de vida, sejam atingidos de forma cada vez mais intensa.

Esse contexto de agravamento da injustiça ambiental, somado ao adoecimento em razão da Covid 19, vitimou fatalmente muitos catadores, mortes cujos números reais não são detectados, tendo em vista a subnotificação. Os dados empíricos apontam, de todo modo, para um número alarmante, uma vez que Duque de Caxias, segundo dados veiculados pela mídia, é o segundo município em índice de óbitos por Covid 19. (Disponível em: https://diariodorio.com/caxias-passa-de-12-mil-casos-confirmados-de-covid-19-e-drauziovarella-chama-prefeito-de-irresponsavel/)

Portanto, o "território do lixo" se constitui através do lixão de Jardim Gramacho e de seu entorno, através do registro de desigualdade socioambiental que acomete não somente o ambiente, mas sobretudo a população, tornando urgente que se busquem caminhos para fazer valer a justiça ambiental que, segundo Acselrad (2004), deve ser efetivar pela:

\footnotetext{
"Busca do tratamento justo e do envolvimento significativo de todas as pessoas, independentemente de sua raça, cor, origem ou renda no que diz respeito à elaboração, desenvolvimento, implementação e reforço de políticas, leis e regulações ambientais. Por tratamento justo entenda-se que nenhum grupo de pessoas, incluindo-se aí grupos étnicos, raciais ou de classe, deva suportar uma parcela desproporcional das consequências ambientais negativas resultantes de operações industriais, comerciais e municipais, da execução de políticas e programas federais, estaduais, locais ou tribais, bem como das consequências resultantes da ausência ou omissão destas políticas" (ACSERALD, 2004).
}

Faz-se necessário trazer esse conceito para o debate, considerando que o sub-bairro de Jardim Gramacho é constituído em sua maioria de pessoas negras e/ou migrantes da 
Catadores de materiais recicláveis e a Covid 19: impactos no trabalho diante da pandemia Valéria Pereira Bastos

região Nordeste do país, com baixa escolaridade, e que enfrentavam no seu cotidiano o desafio de sobreviver diante das inúmeras violências ocorridas tanto no trato com atividade de catação penosa, perigosa e insalubre, quanto no atendimento das diversas demandas, conforme sinaliza Bastos (2014), quando descreve a situação do município de Duque de Caxias, ressaltando as questões do sub-bairro (2014):

\footnotetext{
"Através deste pequeno desenho do sub-bairro de Jardim Gramacho, podemos enfatizar que ele expressa o que vem sendo apresentado no cenário de milhares de bairros brasileiros, ou seja, é mais um local periférico que revela uma grande desigualdade social atrelada a outros tipos de desigualdades, como por exemplo a ambiental, por abrigar um dos maiores aterros de lixo da América Latina, o que coloca em debate os riscos ambientais aos quais a população residente e trabalhadora está exposta” (BASTOS, 2014,p. 115).
}

Conjugado às inúmeras expressões já apontadas, buscou-se verificar que ações têm sido realizadas pelo poder público no sub-bairro junto às 15 cooperativas existentes, no sentido de suprir as necessidades básicas de catadores e catadoras remanescentes do lixão que ainda permanecem em Jardim Gramacho, ligados às cooperativas. É sabido que a atividade de coleta e triagem de resíduos sólidos se constitui como um risco de contágio do Novo Coronavírus para os que participam da coleta seletiva e da cadeia da reciclagem, sobretudo na atividade de triagem, pelo fato da contaminação não ocorrer somente pelo ar, mas também por manuseio de objetos e, principalmente de resíduos sólidos urbanos. Sendo assim, é fundamental que haja novas alternativas de tratamento para prevenção e cuidados necessários à saúde desses trabalhadores.

O que pudemos apurar, através da abordagem realizada com as lideranças locais, foi que das 15 cooperativas existentes, 10 ficaram totalmente fechadas e 5 atuaram com muita dificuldade, ou seja, o comprometimento em termos de ganhos para a sobrevivência foi atingido quase que na sua totalidade. Soma-se a isso o fato de que nem todos os catadores e catadoras foram contemplados com o auxílio emergencial disponibilizado pelo governo no valor de $\mathrm{R} \$ 600,00$; uns pelo comprometimento nos documentos, outros devido à dificuldade de acesso à rede de internet para cadastramento, dentre outras dificuldades, inclusive ausência de documentos de identificação.

Mas a mobilização social foi preponderante, ocupando um lugar de destaque, sobretudo nas regiões menos assistidas pelo poder público, a qual, através da doação de cestas básicas e material de higiene pessoal, buscou atender de forma emergencial as cooperativas existentes e a população residente no sub-bairro de Jardim Gramacho.

Cabe ressaltar a relevância do nível de resistência dessa população, demonstrada a 


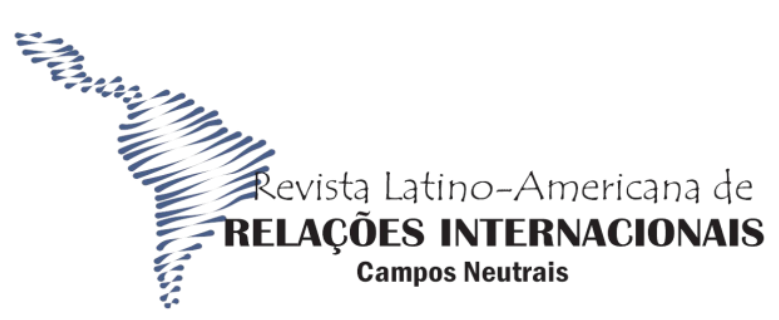

partir dos movimentos populares e sociais pelo viés da solidariedade ativa que vem promovendo inúmeras ações de socorro, embora saibamos que estas não substituem a política pública, mas suprem em parte a necessidade daqueles que, por questões alheias às suas vontades, não se encontram em condições de supri-las a partir do trabalho.

Ressalta-se com especial atenção o processo de mobilização que vem sendo realizado para atender as demandas da população do sub-bairro de Jardim Gramacho, território estigmatizado por ter abrigado por mais de trinta anos o maior lixão da América Latina, e que, até os dias atuais, permanece como uma zona de sacrifício (ACSERALD, 2004) ou expressivo bolsão de miséria. A rede de solidariedade ativa vem ganhando dimensão expressiva, e atendendo quase em sua totalidade as demandas locais através de inúmeras campanhas. Ao mesmo tempo cabe registrar que, se há uma efetiva manifestação advinda da sociedade civil, o poder público segue alheio ao atendimento da população, pois a cada dia vem precarizando o acesso aos direitos oriundos tanto da assistência social como das diversas outras políticas públicas.

\section{Considerações Finais}

O Novo Coronavírus trouxe impactos profundos em nossa sociedade. Apesar dos esforços iniciais de combate à pandemia, a falta de articulação política entre os entes federativos e a criminosa negligência do governo federal vêm forjando uma crise epidemiológica sem precedentes e com retornos ainda infelizmente incertos.

A população de catadores e catadoras no Brasil se viu ameaçada pela falta de trabalho, aliada à dificuldade de acesso ao recebimento do auxílio emergencial "concedido" pelo governo, o que os torna duplamente excluídos de acesso aos bens e serviços públicos.

No caso do sub-bairro de Jardim Gramacho, durante o quadro instalado da pandemia, aqui retratado, foi possível identificar que a situação que ocorria durante o funcionamento do lixão, permeada por expressões da questão social, dentre elas a exploração da mão de obra em todos os sentidos, foi visivelmente agravada pela necessidade de isolamento e paralisação quase que total das atividades de separação de materiais recicláveis, em razão da natureza do processo de contaminação e da ausência de infraestutura para tratar os resíduos, conforme já sinalizado.

Neste sentido, consideramos que o papel da gestão pública seria de fundamental

\begin{tabular}{|l|l|l|l|} 
Rio Grande & v. 3, n. 1 & p. 118-132 Jan-Abril 2021 \\
\hline
\end{tabular}


Catadores de materiais recicláveis e a Covid 19: impactos no trabalho diante da pandemia

Valéria Pereira Bastos

relevância para prestar apoio necessário na perspectiva de garantir a sobrevivência desse contingente de trabalhadores, que - em nome da manutenção da saúde - não teve como manipular os materiais potencialmente recicláveis através de práticas sanitárias e ambientalmente adequadas no tratamento dos resíduos sólidos. Bem como também não foi apoiada em sua totalidade pelo pagamento de auxílio emergencial de $\mathrm{R} \$ 600,00$, conforme se viu, ficando à mercê da rede ativa de solidariedade, que não substitui o papel das políticas públicas

Sendo assim, consideramos que seja necessário, para a retomada das atividades, envidar esforços públicos e privados na busca de garantir que ações socioambientais corretas e seguras sejam estruturadas, com a finalidade de manter o trabalho de coleta e separação que vinha sendo promovido pelas organizações de catadores no sub-bairro. Desse modo, será possível desconstruir não somente o conceito de zona de sacrifício e/ou paraíso de poluição atribuído àquele espaço, mas romper com o racismo e a injustiça ambiental na perspectiva da equidade. Essa política será enfim capaz de reposicionar esses segmentos de trabalhadores para a construção de desafios que permitam que concorram no mesmo padrão de igualdade como todos os trabalhadores do país.

\section{Referências}

ASSOCIAÇÃO BRASILEIRA DE ENGENHARIA SANITÁRIA E AMBIENTAL. O impacto da pandemia pela covid-19 na gestão dos resíduos sólidos urbanos situação das capitais brasileiras. Disponível em: http://abes-dn.org.br/wp-content/uploads/2020/08/Pesquisa-ABES-2.1Pandemia-COVID-19-RSU-Capitais-26.8.2020-2.pdf. Acessado em 27 de ago. 2020.

ACSERALD, Henri. Justiça ambiental e construção social do risco. Desenvolvimento e Meio Ambiente. Paraná, Editora UFPR, n. 5. 49-60, jan - jun. 2002.

De "bota-foras" e "zonas de sacrifício" - um panorama dos conflitos ambientais no Estado do Rio de Janeiro. In: ACSELRAD, H. (Org.) Conflito social e meio ambiente no Estado do Rio de Janeiro. Rio de Janeiro: Relumé - Dumará, p. 7-18 2004.

BASTOS, V. P. Construindo identidades: catador - herói ou sobrevivente da perversa forma de catação. Confluências, Revista Interdisciplinar de Sociologia e Direito da UFF, Rio de Janeiro, v.4, n. 01, p. 22-26, out. 2005.

Profissão Catador: Um estudo do processo de construção de identidade. Rio de Janeiro: Letra Capital. 2014.

BRASIL, Política a Nacional de Resíduos Sólidos. 2010. Disponível em: http://www.planalto.gov.br/ccivil_03/_ato2007-2010/2010/lei/112305.htm. Acessado em 27 de jun. 2020.

FORTES, Alexandre; OLIVEIRA, Leandro Dias de; SOUSA, Gustavo Mota. A COVID-19 na Baixada Fluminense: Colapso e apreensão a partir da periferia metropolitana do Rio de Janeiro. Espaço e Economia. Revista Brasileira de Geografia Econômica. Ano IX, 2020. Disponível em: https://journals.openedition.org/espacoeconomia/13591?lang=fr. Acessado em 25 de jan. 2021. 

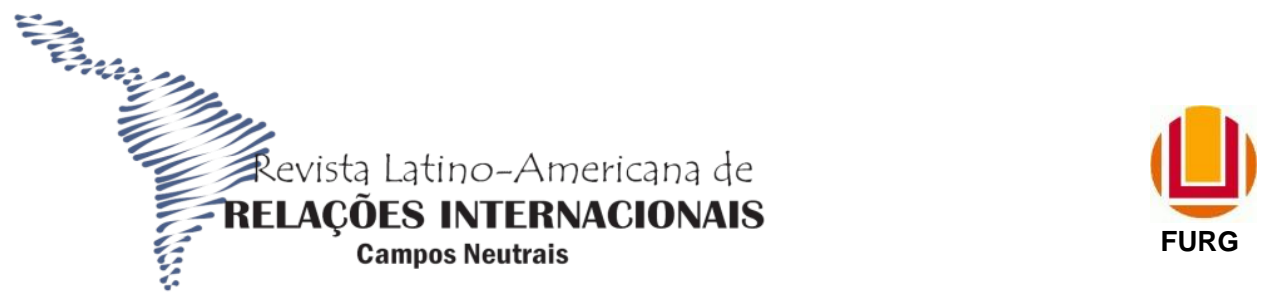

MARX, Karl. Crítica da economia política. Rio de Janeiro: Civilização brasileira. 2016.

NETTO, J.P. Crise do capital e consequências societárias. Serviço Social e Sociedade, São Paulo, v.111, p. 413-429, jul./ set., 2012.

NUNES, Leticia. S.; SILVA, Amanda. G. de M. A concepção de questão socioambiental e o serviço social. Temporalis. Brasília, ano 13, n. 26, p. 97-116, jul./dez. 2013.

SILVA, Lays Helena Paes e. Ambiente e justiça: sobre a utilidade do conceito de racismo ambiental no contexto brasileiro. E-CadernosCES, n. 17, p. 85-111, 2012.

SILVA, Maria Ozanira da Silva e. Pobreza, desigualdade e políticas públicas: caracterizando e problematizando a realidade brasileira. Katálysis. Florianópolis v. 13 n. 2 p. 155-163 jul./dez. 2010. VIÉGAS, Rodrigo Nuñez. Desigualdade Ambiental e “Zonas de Sacrifício”. Disponível em:

https://www.faneesp.edu.br/site/documentos/desigualdade ambiental zonas sacrificio.pdf. Acesso em: 12 de jul. 2020. 